Eixo Roda, Belo Horizonte, v. 28, n. 3, p. 267-273, 2019

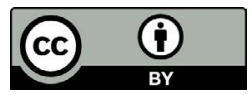

\title{
FONSECA, Rubem. Calibre 22. Rio de Janeiro: Nova Fronteira, 2017.
}

\author{
Davi Andrade Pimentel \\ Universidade Federal Fluminense (UFF), Niterói, Rio de Janeiro / Brasil \\ davi_a_pimentel@yahoo.com.br
}

\begin{abstract}
Houve época em que pensei em me tornar escritor, mas verifiquei que não era louco o suficiente para tanto. Acho que o sujeito que é escritor, em princípio, não é muito bom da cabeça.

(Rubem Fonseca. Vastas emoções e pensamentos imperfeitos.)
\end{abstract}

Antes mesmo de nos aventurarmos pela última coletânea de contos curtos do escritor Rubem Fonseca, Calibre 22, é de extrema importância constatarmos que, com seus mais de noventa anos de idade, ele ainda continua dedicado à escrita literária e a essa exigência imperiosa que, segundo o escritor Maurice Blanchot, se assenhora daqueles que escutam o chamado da literatura: "Escrever é o interminável, o incessante" (BLANCHOT, 1987, p. 17). Ou como diz Roger Laporte, em Études: "A exigência de escrever é tão severa, tão completa, que o escritor é inevitavelmente tentado a contornar, a se desviar, e mesmo se fazer de surdo a um chamado que nada diz, mas que ele não cessa de ouvir" (LAPORTE, 1990, p. 183, tradução minha). Fonseca parece não querer, nem pretender, se desviar dessa exigência. Ele, ao contrário, se abandona de modo bastante crítico e bem sarcástico a esse escrever, a essa árdua tarefa chamada literatura - e os seus mais recentes contos estão aqui como prova disso.

Em seu conto "O intrépido" temos um vislumbre do seu pensamento cáustico sobre essa exigência literária: 
Então lembrei que li não sei onde que muitos escritores eram suicidas e em seguida tinha uma lista com nomes de escritores que se mataram. Não sei mais o nome deles, acho que ninguém sabe, hoje ninguém lê livros de ficção, deve ser por isso que esses sujeitos se mataram (FONSECA, 2017, p. 31-2).

Aqui, revela-se uma autoironia de Fonseca, sendo ele próprio escritor de ficção, na figura de seu narrador debochado e cínico, que, com seu linguajar mordaz, desestabiliza a pretensa estabilidade do seu leitor, jogando na sua cara a pergunta temível: nos dias de hoje, para que serve a literatura quando a leitura ficcional perde cada vez mais espaço para um conteúdo não-literário de rápida absorção e de rápido descarte?

Sem abrir mão de sua habitual ironia, Fonseca esboça algumas respostas alternativas para essa pergunta, todas elas, claro, marcadas por um certo tom zombeteiro característico de sua ficção: "É fácil escrever um livro, surfar é muito mais difícil” (FONSECA, 2017, p. 32). E quanto mais os contos se apresentam repletos de impostura em relação à literatura, mais eles revelam prováveis respostas à sua subsistência, sendo uma delas o ato de leitura. Em Calibre 22, de modo incisivo e, por vezes, agressivo, os narradores-leitores de nove contos - "Fantasmas", "Pródromo", "A morte do ministro", "Cibele", "O morcego, o mico e o velho que não era corcunda - Parte II", "O chapéu-panamá", "Mildred”, "A busca" e "Calibre 22" - defendem o espaço ficcional de todo o livro a partir do ato de ler: ao constantemente mencionarem a leitura de algum texto, ao citarem passagens de escritores renomados e ao relacionarem o sexo e a literatura como duas paixões complementares. O conto "Calibre 22" reúne duas dessas características: "Peguei um livro de poesias para ler. Não sei se já disse que gosto muito de duas coisas, mulher e poesia. Peguei o Ferreira Gullar na estante e fiquei lendo" (FONSECA, 2017, p. 177). A insistência do ato de leitura enquanto modo de reflexão sobre as atitudes humanas e sobre o mundo, que atravessa sobretudo esses nove contos, nos lembra que somente com a existência de leitores a literatura pode sobreviver. Essa insistência é quase um ato panfletário em favor da obra literária para que ela não se perca em meio à superficialidade que acomete a nossa sociedade atualmente - sociedade que é representada, em Calibre 22, pelo narrador do conto "O chapéu-panamá": "Tem gente que diz que gosta de ler. Eu acho ler uma merda, o sujeito tem que ser cretino para ficar sentado olhando as páginas de um livro" (FONSECA, 2017, p. 130). 
Nessa provocativa perspectiva do narrador, a crítica fonsequiana não se refere, como poderia ser esperado, ao seu leitor ou ao leitor de literatura, mas ao não-leitor de literatura, sendo, por conseguinte, uma crítica inversa. E essa crítica se torna bastante categórica por estar em um espaço de leitura, um espaço em que o leitor "cretino" está perdendo tempo "olhando as páginas de um livro". Ao se ver ofendido, o leitor não se demorará muito em um possível constrangimento, pois logo em seguida, através de um riso ácido de Fonseca, que subjaz a todo o conto, esse mesmo narrador que despreza a literatura se tornará um ser viciado em livros justamente porque uma mulher com seu charme e, principalmente, com seu corpo introduzirá nele a paixão pelo literário: "Maria me deu outro livro, e depois outro, e depois outro, e depois outro. Vou thes contar uma coisa. Leiam um livro, não é tão horrível assim. Mas é viciante" (FONSECA, 2017, p. 133). O verbo dar associado à repetição do advérbio depois nos remete de imediato ao ato sexual entre o narrador convertido em leitor e a sua parceira, Maria - sexo que se tornou possível por intermédio da leitura: "Estou viciado em livros e em Maria. Ela está morando comigo há quatro anos. Não quero saber de nenhuma outra mulher" (FONSECA, 2017, p. 133). O riso de Fonseca está em demonstrar que a suposta superioridade masculina cai por terra diante da supremacia do corpo feminino - basta a mulher desejar para o homem ceder: “'Gostaria que você me fizesse um favor', ela disse uma tarde./ 'Que favor?', perguntei, escabreado./ Ela sempre tinha um livro na mão./ 'Que lesse este livro', disse Maria colocando um livro na minha mão" (FONSECA, 2017, p. 132).

Em seus textos, de um modo geral, o machismo de seus narradores, a brutalidade de seus personagens masculinos e a força do macho sucumbem face ao desejo pelo corpo feminino. Desse modo, em combate sexual com a fêmea, o macho fonsequiano perde toda e qualquer batalha. E a literatura, como comprova o conto "O chapéu-panamá", pode tirar muito bem um proveito disso: pode se utilizar da sensibilidade feminina para atingir a brutalidade masculina e assim subsistir. E, com isso, temos uma das possíveis respostas de Fonseca para a pergunta lançada acima: a literatura serve para sensibilizar o macho. Claro, uma resposta digna do escritor, repleta de ironia, mas também envolta por uma certa verdade-clichê: a mulher, através da literatura, pode de alguma maneira sensibilizar o seu parceiro, sensibilizar o seu olhar para o mundo. 
Outro ato de conversão é sugerido pelo conto "A morte do ministro", que segue um roteiro semelhante ao que lemos em "O chapéupanamá"; primeiro, temos o desprezo do macho pelo literário: "Quando a Maria dormia comigo, o que acontecia todos os dias, eu pegava no sono logo. Ela ficava lendo. Porra, lendo livro!” (FONSECA, 2017, p. 67); e, logo depois, a força do feminino: "Eu amava a Maria. Faria tudo por ela. Até leria livros. Quantos? Ah, o amor..." (FONSECA, 2017, p. 72). Em Calibre 22, a mulher é o prazer sexual associado ao ato de leitura, e disso a literatura, à moda fonsequiana, pode tirar proveito.

Com seu cinismo latente, Calibre 22 quer ser também aquele texto

que põe em estado de perda, aquele que desconforta (talvez até um certo enfado), faz vacilar as bases históricas, culturais, psicológicas do leitor, a consistência de seus gostos, de seus valores e de suas lembranças, faz entrar em crise sua relação com a linguagem" (BARTHES, 2004, p. 20-21).

Sem deixar de lado a sua dubiedade do dizer, Fonseca faz rever, ou deseja fazer rever, certos preconceitos que estão presentes nas opiniões e, sobretudo, nos crimes de ódio contra aqueles que se afastam de uma norma pretensamente estabelecida há tempos em nossa sociedade. Em quatro contos, Fonseca trabalha a temática da homossexualidade e da transexualidade de modo bastante cortante. Em "Colégio", o narrador, mesmo afirmando não ter "nada contra veados, bom, mas não queria ter um irmão veado, nem um primo veado, nenhum veado na família" (FONSECA, 2017, p. 38), o que reafirma o preconceito alimentado pelo seu entorno familiar, é o único do colégio que enfrenta a Gangue dos Tiradentes para defender um colega veado que "não consegue fingir que não é" (FONSECA, 2017, p. 38). É importante ressaltar que, apesar de ter um juízo de valor pejorativo em relação ao homossexual, o narrador do conto se mostra sensível à situação humilhante pela qual passa o seu colega de turma: a sensibilidade nesse momento supera o preconceito enraizado. Fonseca nos faz rever, a partir de sucessivas e cruéis inversões de valores, o nosso comportamento em relação ao outro - o outro dado como ser inferior. Em "Cibele", nos é apresentada uma transexual por quem o narrador macho se apaixona e, obviamente, por ser macho, não pode viver essa paixão, o que demarca o preconceito preexistente em muitos homens em relação à mulher que antes habitara um corpo masculino. 
Em "O morcego, o mico e o velho que não era corcunda", o narrador oferece a sua casa para que o seu ex-vizinho Otávio, "que é homossexual, talvez por isso seja tão simpático e culto" (FONSECA, 2017, p. 103), possa morar após ser mandado embora da escola em que trabalhava quando souberam de sua orientação sexual. Logo após a mudança, Otávio é morto por seu namorado que o acusava de lhe dever dinheiro. Com sua boa vontade e com juízos de valor um tanto estereotipados, "[o]s homossexuais, principalmente os masculinos, sofrem muito. Li num livro que ninguém sabe quando uma mulher é homossexual, a não ser que ela queira" (FONSECA, 2017, p. 105-106), José, o narrador do conto, decide vingar o seu finado hóspede. E a vingança não é perpetrada porque o ex-vizinho era homossexual. Aqui o que está em jogo é a pessoa de Otávio, não a sua sexualidade, o que nos leva a refletir, por meio da escrita fonsequiana, que antes de toda e qualquer sexualidade existe um ser que deve ser respeitado - o outro deve ser respeitado.

Em se tratando de respeito para com o outro, o conto "Mildred" é bastante significativo. Jonas, o narrador do conto, é um matador de aluguel fora da ativa que deseja voltar a matar para arrecadar dinheiro e, assim, reconquistar a mulher amada com a compra de um grande apartamento. Ele recebe missões de Beto Bicheiro para matar homossexuais dadas por um cliente abastado. Em todos os assassinatos, Jonas não deixa de refletir sobre aquelas mortes, em especial a morte de um milionário que financiava organizações a favor das minorias. Jonas, diferente de seu cliente, nada tinha contra os homossexuais, pois acreditava que "a pessoa tem o direito de ser quem ela é. Ser homossexual é uma normalidade, não é um defeito físico ou mental ou social ou moral ou outra porra qualquer" (FONSECA, 2017, p. 139).

Mas, mesmo tendo essa postura, Jonas somente decide parar de matar quando consegue arrecadar o dinheiro para o apartamento, o que evidencia o seu egoísmo em relação à vida do outro. Contudo, esse egoísmo será contrabalanceado com certo altruísmo que colocará um fim no mandante das execuções dos homossexuais: o comendador Moura Barros, presidente da Associação de Proteção dos Valores Morais, "um homofóbico doente" (FONSECA, 2017, p. 145). É verdade, o respeito para com o outro somente foi validado quando o interesse individual foi alcançado, o que não deixa de ser contraditório. No entanto, não podemos esquecer que do egoísmo surgiu a vontade de pôr fim às mortes futuras de 
outros homossexuais. Claro que uma morte não vale por várias vidas, mas é a partir desses valores distorcidos, ambíguos e, por que não, sórdidos do seu narrador que a escrita de Fonseca nos faz pensar nos crimes de ódio contra os homossexuais e contra toda e qualquer minoria. E, com isso, temos uma segunda resposta possível de Fonseca para a pergunta lançada anteriormente: a literatura serve para nos fazer refletir sobre os nossos atos, ideias e valores em relação ao outro e ao mundo. Em Calibre 22, o egoísmo e o altruísmo se mesclam, ou melhor, se corrompem a ponto de um ser a imagem do outro, imagem que é também a do leitor que o lê e a do homem que esteve, está e estará presente no mundo.

Calibre 22 provoca o leitor, incita-o a ler, a pensar, a refletir, a ser curioso, a criar, sendo essas, portanto, algumas das alternativas de Fonseca para responder sobre a importância da literatura em tempos tão sombrios. E muitas outras alternativas surgem ao longo da leitura de seu último livro. Nada está dado de antemão, tudo ainda está por ser dito, pois o seu texto é de uma pluralidade que excede qualquer ponto final. Além de um trabalho propriamente reflexivo com altas doses de ironia, crueldade e escárnio, Fonseca executa também um trabalho metalinguístico excelente, citando diversos escritores brasileiros e encorajando, assim, o seu leitor a partir para outras obras literárias para que a literatura possa, dessa forma, subsistir e se perpetuar: "Um escritor disse que viver é muito perigoso" (FONSECA, 2017, p. 129). Qualquer referência ao Grande sertão: veredas, de Guimarães Rosa, não seria mera coincidência, mas uma proposta para manter viva a palavra literária: uma questão de sobrevivência da literatura. Fonseca constrói, a seu modo, uma corrente literária que faz ecoar outras obras e, nessa reverberação literária, o que antes fora escrito, como, por exemplo, a própria obra rosiana, passa a ser atualizado a partir do conto no qual está inserida a sua referência. E, dessa maneira, a obra atualizada por Fonseca passa a se tornar atual para o leitor de seu conto - e essa atualização poderá ter como resultado uma possível leitura da obra referida, o que por si só seria de grande valia para a sobrevivência da palavra literária: essa é uma das contribuições de Calibre 22 à literatura.

Por trás do seu tom zombeteiro, Fonseca nos lembra que somos feitos de palavras e é por meio delas que nomeamos o mundo e nos nomeamos, por isso a importância da literatura, que, por sua vez, trabalha a palavra para além do senso comum, oferecendo-nos uma possibilidade de ver o mundo para além de uma superficialidade embotada. A literatura 
nos descentra e, nesse descentramento, nos despe e nos impulsiona a olhar para o mais íntimo de nós mesmos - ela nos põe a nu diante de um espelho fragmentado. É por esse motivo que Fonseca sempre está aberto ao chamado incessante da literatura, a esse escrever interminável, pois escrever é ter a consciência de que existir no mundo é um ato que somente pode se dar através da palavra.

\section{Referências}

BARTHES, Roland. O prazer do texto. Tradução de J. Guinsburg. São Paulo: Perspectiva, 2004.

BLANCHOT, Maurice. O espaço literário. Tradução de Álvaro Cabral. Rio de Janeiro: Rocco, 1987.

FONSECA, Rubem. Calibre 22. Rio de Janeiro: Nova Fronteira, 2017. LAPORTE, Roger. Études. Paris: P.O.L. Éditeur, 1990.

Recebido em: 14 de junho de 2018. Aprovado em: 6 de dezembro de 2018. 